Supplement of The Cryosphere, 8, 1479-1496, 2014

http://www.the-cryosphere.net/8/1479/2014/

doi:10.5194/tc-8-1479-2014-supplement

(c) Author(s) 2014. CC Attribution 3.0 License.

The Cryosphere

(ब) (1)

Supplement of

A 10 year record of black carbon and dust from a Mera Peak ice core
(Nepal): variability and potential impact on melting of Himalayan glaciers

P. Ginot et al.

Correspondence to: P. Ginot (patrick.ginot@ird.fr) 


\section{Supplement material:}

EOF analyses for tracers analyzed in the ice core. Each tracer has the same weight. :

\begin{tabular}{|c|c|c|c|}
\hline \multicolumn{5}{|c|}{ Eigenvalues : Mera core - all data } \\
\hline & Fact. 1 & Fact. 2 & Fact. 3 \\
\hline Fluor & $-0,622490$ & $-0,531500$ & 0,257512 \\
\hline Chlore & $-0,361453$ & 0,836228 & 0,238047 \\
\hline Nitrate & $-0,724551$ & $-0,094188$ & 0,277106 \\
\hline Sulfate & $-0,670337$ & 0,202101 & $-0,036094$ \\
\hline Lithium & $-0,251566$ & 0,441002 & 0,037949 \\
\hline Sodium & $-0,164263$ & 0,812900 & 0,124957 \\
\hline Ammonium & $-0,636851$ & $-0,357502$ & 0,587836 \\
\hline Potassium & $-0,510127$ & 0,784596 & 0,127002 \\
\hline Magnesium & $-0,836455$ & $-0,014417$ & $-0,497512$ \\
\hline Manganese & $-0,794118$ & $-0,065939$ & $-0,533665$ \\
\hline Calcium & $-0,763636$ & 0,122433 & $-0,354637$ \\
\hline rBC & $-0,714281$ & $-0,260721$ & 0,339868 \\
\hline Dust & $-0,446027$ & $-0,281453$ & $-0,607116$ \\
\hline $\boldsymbol{\delta}^{\mathbf{1 8}} \mathbf{O}$ & $-0,601770$ & $-0,287453$ & 0,409850 \\
\hline
\end{tabular}

\begin{tabular}{|c|c|c|c|c|}
\hline \multicolumn{5}{|c|}{ Mera core - all data } \\
\hline & Eigenvalue & \% Total - variance & Cumul - Eigenvalue & Cumul - \% \\
\hline $\mathbf{1}$ & 5,233227 & 37,38020 & 5,23323 & 37,3802 \\
\hline $\mathbf{2}$ & 2,879539 & 20,56814 & 8,11277 & 57,9483 \\
\hline $\mathbf{3}$ & 1,889964 & 13,49975 & 10,00273 & 71,4481 \\
\hline $\mathbf{4}$ & 1,385331 & 9,89522 & 11,38806 & 81,3433 \\
\hline $\mathbf{5}$ & 0,780434 & 5,57453 & 12,16850 & 86,9178 \\
\hline $\mathbf{6}$ & 0,531135 & 3,79382 & 12,69963 & 90,7117 \\
\hline $\mathbf{7}$ & 0,334221 & 2,38729 & 13,03385 & 93,0989 \\
\hline $\mathbf{8}$ & 0,329558 & 2,35398 & 13,36341 & 95,4529 \\
\hline $\mathbf{9}$ & 0,225984 & 1,61417 & 13,58939 & 97,0671 \\
\hline $\mathbf{1 0}$ & 0,160791 & 1,14850 & 13,75018 & 98,2156 \\
\hline $\mathbf{1 1}$ & 0,107045 & 0,76461 & 13,85723 & 98,9802 \\
\hline $\mathbf{1 2}$ & 0,099302 & 0,70930 & 13,95653 & 99,6895 \\
\hline $\mathbf{1 3}$ & 0,037835 & 0,27025 & 13,99437 & 99,9598 \\
\hline $\mathbf{1 4}$ & 0,005634 & 0,04024 & 14,00000 & 100,0000 \\
\hline
\end{tabular}
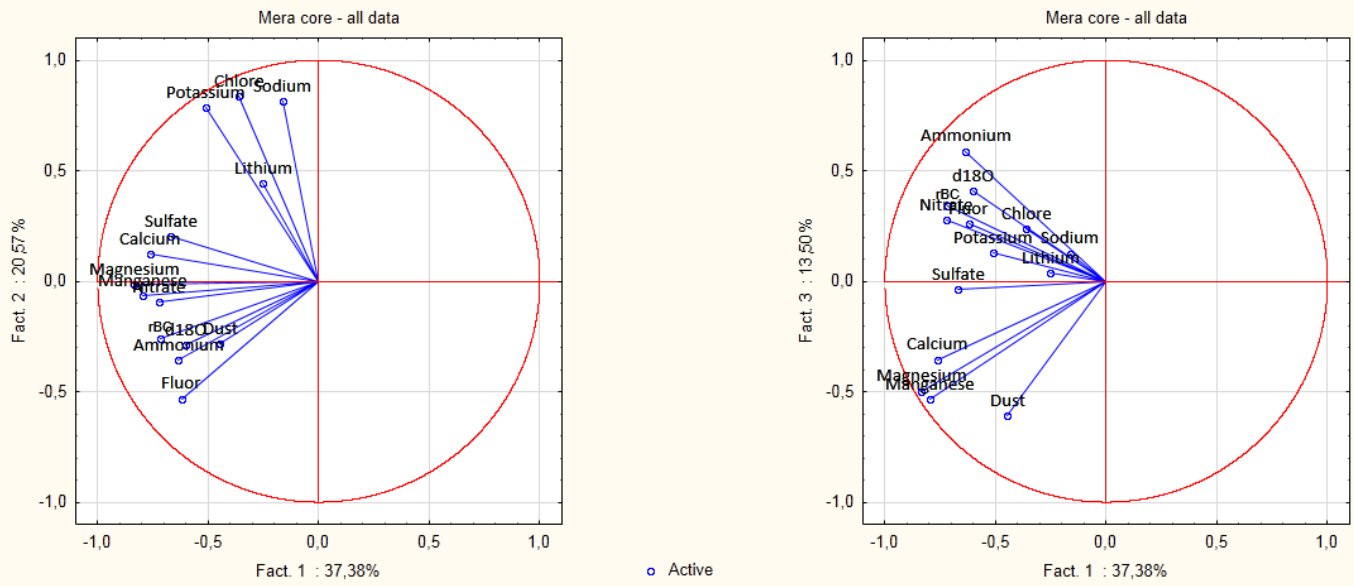


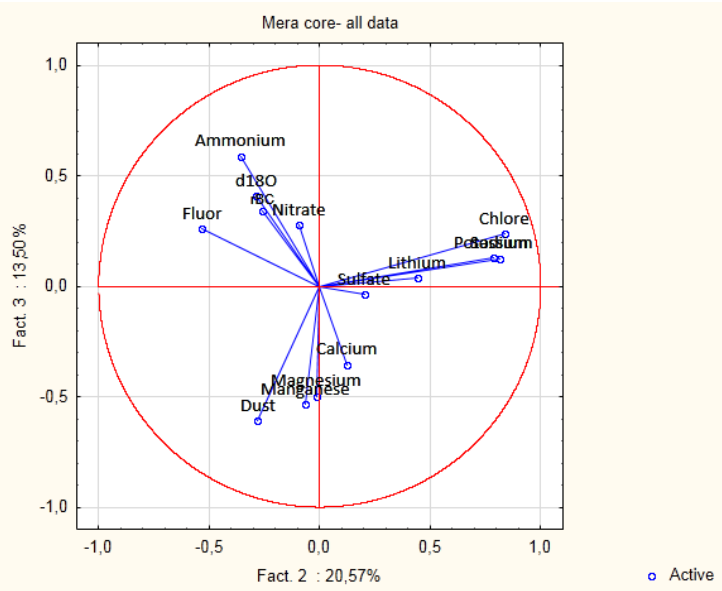

